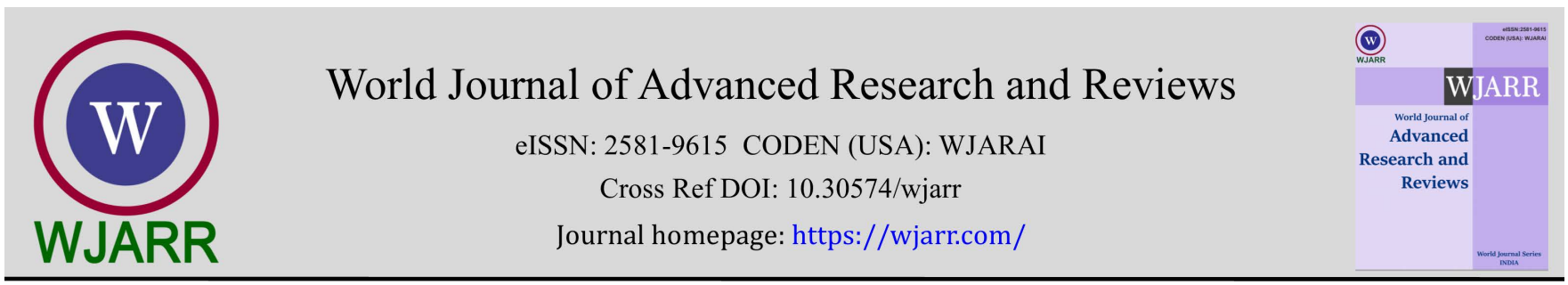

(RESEARCH ARTICLE)

Check for updates

\title{
Puerperal depression among women attending postnatal clinic in Port Harcourt Nigeria
}

\author{
Nonyenim Solomon Enyidah $1{ }^{*}$ and Esther Ijeoma Nonye-Enyidah ${ }^{2}$ \\ ${ }^{1}$ Department of Medicine, Faculty of Clinical Sciences, College Health Sciences, Rivers State University, Port Harcourt, Rivers \\ State Nigeria. \\ 2 Department of Obstetrics and Gynaecology, Rivers State University Teaching Hospital, Port Harcourt, Rivers State, \\ Nigeria.
}

World Journal of Advanced Research and Reviews, 2022, 13(01), 710-717

Publication history: Received on 17 December 2021; revised on 27 January 2022; accepted on 29 January 2022

Article DOI: https://doi.org/10.30574/wjarr.2022.13.1.0071

\begin{abstract}
Background: Puerperal depression is the most common of the mood disorders occurring within the first six weeks postpartum. It affects more than $15 \%$ of women across the globe and constitutes a considerable public health problem for the women and their families. It accounts for more than $20 \%$ of maternal deaths after child birth. Children of mothers with puerperal depression are likely to suffer severe behavioral problems. It is therefore imperative that factors that contribute to it be identified and considered in their management.
\end{abstract}

Objectives: To determine the prevalence, risk factors and possible predictors of puerperal depression.

Methods: women visiting the postnatal clinic six weeks after child birth, who met the study inclusion criteria and consented to the study were interviewed, and screened for depression using a socio-demographic risk factor questionnaire and the Edinburg postnatal depression scale (EPDS). Using the statistical package for social sciences (SPSS) version 23.0, data obtained was analyzed. P-values $<0.05$ were statistically significant.

Results: Four hundred and five (405) women consented to the study and 135, (33.3\%) had depression. Among the risk factors isolated, cohabitation, poor emotional and social support, partner violence, mode of delivery, death of children and children's health challenges were predictive risk factors for puerperal depression.

Conclusion: There is a need for urgent overhaul of social systems that favor women before and during pregnancy and after childbirth which will consider these predisposing predictive factors in their management.

Keywords: Puerperal depression; Socio-demographic factors; EPDS; Obstetrics history; Predictors; Social support

\section{Introduction}

Postnatal period is well documented and known as a period with increased risks of serious mood disorders. Postpartum depression is the most common of the mood disorders occurring within the first six weeks postpartum and affecting more than $15 \%$ of women [1]. It represents a considerable public health problems affecting women and their families. The symptoms are devastating and handicapping in severe cases leading to suicide. It accounts for more than $20 \%$ of maternal deaths after childbirth [2,3]. It is the second cause of disability next to HIV/AIDS, posing lots of complications to childbirth. It affects breastfeeding leading to malnutrition and weak immune system which predisposes babies to

\footnotetext{
* Corresponding author: Nonyenim Solomon Enyidah

Department of Medicine, Faculty of Clinical Sciences, College Health Sciences, Rivers State University, Port Harcourt, Rivers State Nigeria.
}

Copyright $(2022$ Author(s) retain the copyright of this article. This article is published under the terms of the Creative Commons Attribution Liscense 4.0. 
illnesses [4,5]. It has a silent but selective effect on the mother-infant relationship, child growth and development. It is said that young children of mothers with postpartum depression have greater behavioral problems than those of nondepressed mothers [6].

Risk factors predisposing women to puerperal depression have been discussed across the globe without reaching a complete consensus [7]. Studies have implicated young maternal age 12-18yr, unplanned pregnancy, poor social support, single marital status, partner violence, poor income, low educational status, poor obstetrics history, multiparity, caesarean sections, mother's mental and physical health and child gender as strong risk factors and possible predictors of puerperal depression $[8,9,10,11,12]$.

Studies in Africa have reported a low prevalence in Uganda (7.1\%), and high prevalence in Zimbabwe (33\%) [13]. In Nigeria, several studies have been carried out in the west, north and eastern parts of the country highlighting the various risk factors and discussing effects of some traditional practices relating to childbirth, but no studies have considered this all important health issue in Port Harcourt South/South Nigeria [10,11, 14, 15, 16, 17, 18, 19 20]. This study intends to report on the prevalence of puerperal depression in a teaching hospital in Port Harcourt and possibly highlight on the predictors.

\section{Material and methods}

\subsection{Study setting and population}

The study was carried out in Rivers State University Teaching Hospital Port Harcourt, Nigeria. The hospital provides unrestricted services to the entire region of the south/south in Nigeria. The postnatal clinic of the hospital sees all women and mothers who must have been delivered of babies within the hospital in the last six weeks. The clinic therefore reviews the health conditions of women and their children six weeks postpartum. The study was a crosssectional questionnaire study, conducted in the postnatal clinic between $1^{\text {st }}$ of March to $1^{\text {st }}$ of June 2020 . It included all women who were delivered of babies within the hospital in the past six weeks, who were visiting the postnatal clinic for review during the period, who had a minimum of primary education and who were in good physical and mental health and were not psychotic. All women who met the inclusion criteria were properly briefed about the study and were requested to sign a consent form. Only women who consented to the study were allowed to take part in the study.

\subsection{Data collection}

Data was obtained by means of personal interview with respondents. Each respondent had two questionnaires; one was the study designed questionnaire, which accommodated socio-demographic variables and risk factors. The second was the English version of Edinburg postnatal depression scale (EPDS). The study design questionnaire has three sections which covered the socio-demographic variables of the respondents, socio-economic variables and obstetrics history including child sex preference.

\subsection{Study instrument, the EPDS}

Puerperal depression was measured using the EPDS, developed by Cox et. al (1987), which have been validated for detecting depression in both antepartum and postpartum and is globally used to screen for depression postpartum $[21,22,23]$. It contains 10 specific questions with four likert scale response options (most of the time, sometimes, not often and never), targeting stress indicators within the previous week. It has a sensitivity and specificity of $86 \%$ and $76 \%$ respectively. Scores are recorded as $0,1,2,3$ or $3,2,1,0$, according to symptom severity. Using the English version, respondents who scored 12 points and above were considered as likely depressives.

\subsection{Data Analysis}

Using the statistical package for social sciences SPSS version 23.0, all relevant descriptive statistical variables were computed using student t-test and chi-square tests and associations between means of continuous variables and categorical variables were determined. Linear multiple regression analysis was used to determine the predictors of postnatal depression from a set of significant associations at bivariate analysis $(\mathrm{p}<0.05)$.

\section{Results}

During the period of the study, 490 women attended the postnatal clinic for their six weeks post- delivery review. 405 consented to the study and participated. 135 (33.3\%) of the respondents had EPDS score of 12 points and above, giving 
a prevalence rate of $33.3 \%$ for puerperal depression. Socio-demographic characteristics of respondents with their risks of depression is shown in table 1.

Table 1 The socio-demographic characteristics of the study population with their risk of depression

\begin{tabular}{|c|c|c|c|c|}
\hline Variables & Frequency (\%) & Risk of depression & Risk of depression & p-values \\
\hline Age groups & $\mathrm{N}=405$ & Depressed, $n=135$ & Not depressed, $n=270$ & $P=0.68$ \\
\hline$\leq 19$ & $5(1.2 \%)$ & $3(2.2 \%)$ & $2(0.7 \%)$ & \\
\hline $20-29$ & $133(32.8 \%)$ & $42(31.1 \%)$ & $91(33.7 \%)$ & \\
\hline $30-39$ & $222(54.8 \%)$ & $77(57.0 \%)$ & $145(53.7 \%)$ & \\
\hline $40+$ & $45(11.1 \%)$ & $13(9.6 \%)$ & $32(11.1 \%)$ & \\
\hline Level of education & & & & $\begin{array}{l}\mathrm{P}=0.024 \text { OR:0.95, } \\
95 \% \mathrm{CL}=0.21-4.40\end{array}$ \\
\hline Primary & $7(1.7 \%)$ & $3(2.2 \%)$ & $4(1.5 \%)$ & \\
\hline Secondary & $137(33.8 \%)$ & $57(42.2 \%)$ & $80(29.6 \%)$ & \\
\hline Tertiary & $216(64.4 \%)$ & $75(55.6 \%)$ & $186(68.9 \%)$ & \\
\hline Marital status & & & & $\begin{array}{c}P=0.001, \text { OR:0.174, } \\
95 \% C L=0.05-0.67\end{array}$ \\
\hline Cohabiting & $3(0.7 \%)$ & $3(2.2 \%)$ & $0(0.0)$ & OR:1689.99 \\
\hline Married & $391(96.5 \%)$ & $124(91.9 \%)$ & $267(98.9 \%)$ & \\
\hline Single & $11(2.7 \%)$ & $8(5.9 \%)$ & $3(1.1 \%)$ & \\
\hline Employment status & & & & $P=0.73$ \\
\hline Employed & $126(31.1 \%)$ & $44(32.6 \%)$ & $82(30.4 \%)$ & \\
\hline Unemployed & $279(68.9 \%)$ & $91(67.4 \%)$ & $188(69.6 \%)$ & \\
\hline
\end{tabular}

The mean age of respondents was 38.28 \pm 2.7 years, $(\mathrm{p}=0.68)$ showing no significant association with depression. Seven respondents had primary education out of which 3 were depressed, and $42 \%$ of the depressed sample had secondary education ( $\mathrm{p}=0.024$, OR: $0.96,95 \% \mathrm{cl}=0.21-4.40$. About $96 \%$ of respondents were married, 8 out of 11 single mothers were depressed and all 3 mothers who cohabited had depression, $\mathrm{p}=0.001,0 \mathrm{R}: 0.95,95 \% \mathrm{cl}=0.05-0.67$ with cohabiting having an OR:1689.9. Level of education did not show any significant association with depression $(p=0.73)$.

\subsection{Social support and social history of respondents}

Table 2 describes respondent's social history and support with depression.

Table 2 Respondents social history and social support with depression

\begin{tabular}{|c|c|c|c|c|}
\hline Variable & Frequency /\% & Risk of depression & Risk of depression & P-values \\
\hline Spouse employment & $\mathrm{N}=405$ & Depressed $n=135$ & Not depressed $n=270$ & $\begin{array}{c}\mathrm{P}=0.006, \mathrm{OR}: 0.39 \\
95 \% \mathrm{cl}=0.20-0.77\end{array}$ \\
\hline No & $37(9.1 \%)$ & $20(14.8 \%)$ & $17(6.3 \%)$ & \\
\hline Yes & $368(90.0 \%)$ & $115(85.2 \%)$ & $235(93.7 \%)$ & \\
\hline Support from spouse & & & & $\begin{array}{l}\mathrm{P}=0.001, \mathrm{OR}: 0.24 \\
95 \% \mathrm{cl}=0.10-0.55\end{array}$ \\
\hline No & $26(6.4 \%)$ & $17(12.6 \%)$ & $9(3.3 \%)$ & \\
\hline
\end{tabular}


World Journal of Advanced Research and Reviews, 2022, 13(01), 710-717

\begin{tabular}{|c|c|c|c|c|}
\hline Yes & $379(93.6 \%)$ & $118(87.4 \%)$ & $261(96.7 \%)$ & \\
\hline Fight with spouse & & & & $\begin{array}{c}\mathrm{P}=0.003, \text { OR:3.04, } \\
95 \% c l=1,44-6.41\end{array}$ \\
\hline No & $374(92.3 \%)$ & $117(86.7 \%)$ & $257(92.3 \%)$ & \\
\hline Yes & $31(7.7 \%)$ & $18(13.3 \%)$ & $13(7.1 \%)$ & \\
\hline Family support & & & & \\
\hline No & $165(40.7 \%)$ & $58(43.0 \%)$ & $107(39.6 \%)$ & \\
\hline Yes & $240(59.5 \%)$ & $77(57.0 \%)$ & $163(60.4 \%)$ & \\
\hline
\end{tabular}

Spouses' employment $(\mathrm{p}=0.006)$ and support from spouse $(\mathrm{p}=0,001)$ showed significant association with depression but on multi-variant analysis, OR:0.39, 95\%cl=0.20-0.77, OR:0.24, 95\%cl=0.10-0.55 respectively. Fight with spouse $(\mathrm{p}=0.033), 0 \mathrm{R}: 3.04,95 \% \mathrm{cl}=1.44-6.41$, showed a predictive association with depression.

\subsection{Obstetrics variables with depression}

Table 3 describes maternal obstetrics history with depression.

Table 3 Obstetrics and maternal history with depression

\begin{tabular}{|c|c|c|c|c|}
\hline Variables & Frequency /\% & Risk of depression & Risk of depression & p-values \\
\hline Gestational age & $N=405$ & Depressed n=135 & Not depressed $n=270$ & $P=0,69$ \\
\hline $14-26$ & $30(7.4 \%)$ & $12(8.9 \%)$ & $18(6.7 \%)$ & \\
\hline $27-40$ & $288(71.1 \%)$ & $93(68.9 \%)$ & $195(72.2 \%)$ & \\
\hline $41+$ & $87(21.5 \%)$ & $30(22.2 \%)$ & $57(21.1 \%)$ & \\
\hline Planned pregnancy & & & & $\mathrm{P}=0.81$ \\
\hline No & $104(25.7 \%)$ & $36(26.7 \%)$ & $68(25.2 \%)$ & \\
\hline Yes & $301(74.3 \%)$ & $99(73.3 \%)$ & $202(74.8 \%)$ & \\
\hline $\begin{array}{l}\text { Number of children- family } \\
\text { size }\end{array}$ & & & & $\mathrm{P}=0.401$ \\
\hline 0 & $4(1.0 \%)$ & $2(1.5 \%)$ & $2(0.7 \%)$ & \\
\hline 1 & $183(45.2 \%)$ & $60(44.4 \%)$ & $123(45.6 \%)$ & \\
\hline $2-4$ & $213(52.6 \%)$ & $73(54.1 \%)$ & $140(51.9 \%)$ & \\
\hline $5+$ & $5(1.2 \%)$ & $0(0.0 \%)$ & $5(1.9 \%)$ & \\
\hline Mode of delivery & & & & $\begin{array}{c}\mathrm{P}=0.019 \\
\text { OR:1.68, } \\
\text { 95\%cl=1.10- } \\
2.58\end{array}$ \\
\hline Caesarean section & $227(56.0 \%)$ & $87(64,4 \%)$ & $140(51.9 \%)$ & \\
\hline Vaginal delivery & $178(44.0 \%)$ & $48(35.6 \%)$ & $130(48.1 \%)$ & \\
\hline Death of child/children & & & & $\begin{array}{c}\mathrm{P}=0.001 \\
\text { OR:1.82, } \\
95 \% \mathrm{cl}=1.27- \\
2.62\end{array}$ \\
\hline
\end{tabular}




\begin{tabular}{|c|c|c|c|c|}
\hline 0 & $322(79.5 \%)$ & $92(68.1 \%)$ & $230(79.5 \%)$ & \\
\hline 1 & $69(17.0 \%)$ & $36(26.7 \%)$ & $33(12.2 \%)$ & \\
\hline $2+$ & $14(3.5 \%)$ & $7(5.2 \%)$ & $7(2.6 \%)$ & \\
\hline Child health challenges & & & & $\begin{array}{c}\mathrm{P}=0.002, \\
\mathrm{OR}: 2.9, \\
95 \% \mathrm{cl}=1.46- \\
5.67\end{array}$ \\
\hline No & $366(90.4 \%)$ & $113(83.7 \%)$ & $253(93.7 \%)$ & \\
\hline Yes & $39(9.6 \%)$ & $22(16.3 \%)$ & $17(6.3 \%)$ & \\
\hline Is new baby in good health? & & & & $\begin{array}{c}\mathrm{P}=0.001 \\
\mathrm{OR}: 0.324 \\
95 \% \mathrm{cl}=0.16- \\
0.64\end{array}$ \\
\hline No & $38(9.4 \%)$ & $22(16.3 \%)$ & $16(5.9 \%)$ & \\
\hline Yes & $367(90.6 \%)$ & $113(83.7 \%)$ & $254(94.1 \%)$ & \\
\hline Antenatal care & & & & $\mathrm{P}=0.767$ \\
\hline No & $13(3.2 \%)$ & $5(3.7 \%)$ & $8(3.0 \%)$ & \\
\hline Yes & $392(96.8 \%)$ & $130(96.3 \%)$ & $262(97.0 \%)$ & \\
\hline Preferred child sex & & & & $\begin{array}{c}\mathrm{P}=0.001 \\
\text { OR: } 0.42 \\
95 \% \mathrm{cl}=0.31- \\
0.72\end{array}$ \\
\hline Yes & $200(49.4 \%)$ & $50(37.0 \%)$ & $150(55.6 \%)$ & \\
\hline No & 205 (50.6\%) & 85 (63.0\%) & $120(44.4 \%)$ & \\
\hline
\end{tabular}

The mean gestational age at delivery was $37 \pm 3.8$ weeks $(\mathrm{p}=0.69)$. planned pregnancy $(\mathrm{p}=0.81)$, family size $(\mathrm{p}=0.401)$, antenatal care $(\mathrm{p}=0.767)$. These variables did not show any significant association with depression. Mode of delivery $(\mathrm{p}=0.019), 0 R: 1.68,95 \% \mathrm{cl}=1.10-2.58$, death of children $(\mathrm{p}=0.001), 0 \mathrm{R}: 1.82,95 \% \mathrm{cl}=1.27-2.62$, and child health challenges ( $\mathrm{p}=0.002)$, OR:2.9, 95\% $\mathrm{cl}=1.46-5.67$ showed strong association with depression and turned out predictive. Health of the new baby ( $\mathrm{p}=0.001)$, OR:0.324, 95\% $\mathrm{cl}=0.16-0.64$, preferred child sex showed a strong association on bivariate analysis $(\mathrm{p}=0.001)$ but were not predictive.

\section{Discussion}

The prevalence of puerperal depression in women attending the postnatal clinic six weeks postpartum in a central teaching hospital in Port Harcourt, Nigeria was 33.3\% with EDPS cut off point of $\geq 12$. This finding is consistent with the report of Adeyemo EO et. al (2020) who reported a prevalence of 35.6\% from Lagos in a similar study. Agbaje et. al (2019) reported a prevalence of 34.6\% from Western Nigeria, Natochi Nwosu et. al (2021) reported 37.8\% from Ibadan. Studies from other parts of the country have reported prevalence rates of $14.6 \%, 22.9 \%, 21.8 \%, 10.7 \%$, and $44.5 \%$ from studies conducted under various settings, using different EPDS cut off points. $[14,15,20,16,17]$.

Studies from the African continent reported prevalence rates ranging from 7.1\% in Uganda and 33\% in Zimbabwe (13). Reviews of rates from low and middle income countries by Abel Fekadu (2020) reported a prevalence of 25.8\% and $13 \%$ prevalence 1yr postpartum by Donna Stewart et. al (2003). The difference in these reports from our study is largely due to time of assessment and methods used. Assessment of depression 1yr postpartum would definitely miss out a huge percentage of the patients. In this study, no association was found between the socio-demographic variables of age and employment status. This is in keeping with the views of Donna Stewart et. al, and Adeyemo EO et. al, but at variance with the findings of Agbaje OS et. al, who reported that young mothers of age 15-20yr were more likely to get depressed. 
Maryam Gharedrahmat et. al (2017) reported young motherhood and poor education status as predictors and Troutman et. al (1990) reported young age as different from our findings. In this study, level of education of respondents showed a strong association with depression on bivariate analysis $(\mathrm{p}=0.024)$ and $0 \mathrm{R}: 0.95,95 \% \mathrm{cl}=0.21-4.10$ on multivariate analysis. This is similar to the findings of Maryam Gharedrahmat et. al, the reviews of Abel Fekadu et. al and Donna Stewart et. al. Both reviews also reported single marital status as predictive. While Tungshama et. al discussed type of marriage in their report, this study revealed that cohabiting is predictive of puerperal depression (p=0.001), 0R:1689.9 and being a single mother had a strong association with depression.

Spouse unemployment, support from spouse, and partner violence have been reported as predictors [6, 10, 12]. Several reports across the globe are in agreement with the social variables of poor financial and emotional support as predictors, and this study is in agreement with these findings but reports that spouse unemployment, and support from spouse were not predictive but fight with spouse as very predictive of puerperal depression. Across the globe and in all cultures, unplanned pregnancy, mode of delivery, family size, deaths and poor health of children and in some cases, preference of child sex have been reported as risk factors of puerperal depression. This study revealed that various obstetrics and child related factors were associated with puerperal depression. Gestational age, $(\mathrm{p}=0.69)$, planned pregnancy ( $\mathrm{p}=0.81)$, and parity $(\mathrm{p}=0.401)$ did not show strong association with depression. This is at variance with Blome E et. al (2010), (24) who reported unplanned pregnancy as predictive and Maryam Gharedrahmati et. al who reported parity as predictive (25).

Mode of delivery turned out very predictive in this study ( $\mathrm{p}=0.019), 0 \mathrm{R}: 1.68,95 \% \mathrm{cl}=1.10-2.58,56 \%$ of the respondents were delivered through caesarean section which accounted for the strong association. This is in agreement with the reports from Yiyu Hong-Feng et. al and other research findings [26, 25, 10, 7]. Respondents who had lost children previously, $(p=0.001)$, OR:1.82, 95\%cl=1.27-2.62, who had children with health challenges (p=0.002), 0R:2.9, $95 \% \mathrm{cl}=1.46-5.67$, and had health challenges with their new babies $(\mathrm{p}=0.001)$, showed a strong association with depression with predictive values. This is in keeping with some studies which reported them as predictive $[6,12,26]$. Reports on child sex preference and development of puerperal depression varies between different cultures. A report from China indicated that having a female child could lead to depression [27]. Other studies have also reported a strong association between child sex preference and depression [28, 29]. In this study, preferred child sex showed a strong association with depression but not predictive.

\section{Conclusion}

This study showed a high prevalence rate of 33.3\% for puerperal depression among women attending postnatal clinic at six weeks postpartum. Several risk factors were isolated, but the risk factors of marriage (cohabiting), poor social and financial support from spouse, partner violence, mode of delivery, death of children and poor child health turned out as predictors of puerperal depression. There is a need to review the various social networks and systems that favor women before and during pregnancy, delivery and after childbirth. Simple but effective screening process and methods should be employed in the postnatal clinics considering these predictors of puerperal depression to last beyond the puerperal period.

\section{Compliance with ethical standards}

\section{Acknowledgments}

We sincerely thank all the women who participated in the study, the Doctors who administered the questionnaires, the staff of postnatal clinic for their cooperation and assistance.

\section{Disclosure of conflict of interest}

There is no conflict of interest.

\section{Statement of ethical approval}

was obtained from the hospital's ethics committee.

\section{Statement of informed consent}

All respondents signed a consent form. All relevant authorities consented to the study. 


\section{Authors contribution}

Both authors worked at every stage to develop the script.

\section{References}

[1] O'Hara MW and Swain. Rates and risks of postpartum depression; A meta- analysis. International review of psychiatry. 1996; 8: 37-54.

[2] Lancaster CA, Gold KJ, Flynn HA, Yoo H, Marcus SM, Davis MM. Risk factors for depressive symptoms during pregnancy: A systematic review. Am J Obstet. Gynaecol. 2010; 202: 5-14.

[3] Wesner KL, Moses-Kolko-El, Sit DKY. Postpartum depression; A disorder in search of definition. Arch. Women's Ment. Health. 2000; 13(1): 37-40.

[4] Field T. Postpartum depression effects on early interactions, parenting and safety practices; A review. Infant Behav. Div. 2010; 33(1): 1-6.

[5] Surkan PJ, Kennedy CT, Hurley KM, Black MM. Maternal depression and early childhood growth in developing countries; systematic review and meta-analysis. Bull. World Health Organ. 2011; 8: 606-615.

[6] Donna E Stewart, E. Robertson, Cindy-Lee Dennis, Sherry Grace and Tamara Wallington. Literature review of risk factors and interventions. University Health Network Women's Health Program. 2003.

[7] Hannah P, Adams D, Lee A, Glover V, Sandler M. Links between early postpartum mood and postnatal depression. British Journal of Psychiatry. 1992; 160: 977-980.

[8] Troutman BR, Cutrona CE. Non psychotic postpartum depression among adolescent mothers. Journal of Abnormal Psychiatry. 1990; 99: 69-78.

[9] Boyce PM and Todd AL. increased risk of postnatal depression after emergency caesarean section. Med. J. Aust. 1992; 157: 172-194.

[10] Adeyemo EO, Oluwole E0, Odeyemi KA. Prevalence and predictors of postpartum depression among postnatal women in Lagos Nigeria. Afri. Health Sci. 2020; 20(4): 1943-1954.

[11] Agbaje OS, Anyanwu JI, Umoke PI et.al. Depressive and Anxiety Symptoms and Associated Factors among Postnatal women in Enugu-North Senatorial District, South East Nigeria; A cross sectional study. Arch. Public Health. 2019; 77: 1.

[12] Abel Fekadu Dadi, Emma R, Miller and Lillian Mwanri. Postnatal depression and it's association with adverse infant health outcome in low and middle-income countries; A systematic review and meta-analysis. BMC pregnancy childbirth. 2010; 20: 416.

[13] Parsons CE, Young KS, Rochat T], Kringelbach ML, Stein A. A review of evidence from low and middle-income countries. Br. Med. Bull. 2012; 101(1): 57-79.

[14] Abiodun O Adewuye, Adekunle B Egwanti, Adejare M Lawal. Prevalence of postnatal depression in Western Nigerian women; A controlled study. Int. J. psychiatry clin. Pract. 2005; 9(1): 60-64.

[15] Josephat Maduabuchi C, Odutola I Odetunde, Ikenna KN, Euzebus CE, et. al. Postpartum depression among mothers as seen in hospitals in Enugu South East Nigeria; An undocumented issue. Pan African Medical Journal. 2016; 23: 180.

[16] Abasuibong F, Bassey EA, Eko JU. Postpartum depression among women in Uyo Akwa Ibum State Nigeria. J. Psychiatry. 2008; 6: 65-69.

[17] Uwakwe R. Affective (depression) morbidity in puerperal Nigerin women, validation of Edinburg postnatal scale. Acta. Psychiatry. Scan. 2003; $251-259$.

[18] Obindo TJ. Prevalence and correlates of postpartum depression in a teaching hospital in Nigeria. Highland medical Research Journal. 2014; 13: 71-75.

[19] Ukaegbu CL, Iteke OC, Bakere MO, Agbata AT. Postpartum depression among Igbo women in urban mission hospital, South East Nigeria. Emj. 2012; 11: 29-36. 
[20] Tungchoma FP, Obindo TJ, Armiya'u AY et. al. prevalence and socio-demographic correlates of postpartum depression among women attending postnatal/ children's welfare clinic in a tertiary hospital in Jos Nigeria. Sahel med. J. 2018; 21: 23-30.

[21] Cox JL, Holden JM, Sagovsky R. Detection of postnatal depression; Development of the 10 -item Edinburg postnatal depression scale. Bri. J. psychiatry. 1987; 150: 782- 786.

[22] Murry L, Carother AD. The validation EPDS in a community sample. Br. J. psychiatry, 1990; 157: 288-290.

[23] Chowe-Sundani G, Chipps J. A systematic review of screening instruments for depression for use in antenatal services in low resources settings. BMC. Psychiatry. 2017; 17: 1.

[24] Blome E, Jansen P, Verhult F, Hofman A, Raat H et. al. Perinatal complications increase risks of postpartum depression. The generation R. study. BJOG. 2010; 117: 1390-1398.

[25] Maryam Ghaedrahmati, Ashraf Kazemi and Masood Bahrami. Postpartum depression risk factors.; A narrative review. J. Educ. Health promot. 2017; 6-60.

[26] Yiyu Hong-Feng, Jing Chen, Zhi Bin, Yu Shai Han et. al. Postpartum depression; Current status and possible identification using Biomarkers. Frontiers in psychiatry, mood disorders, Front. Psychiatry. 2021.

[27] Beek CT. postpartum depression; it isn't just the blues. American Journal of Nursing. 2006; 106(5): 40-50.

[28] Boyce P, Hickey A. psychosocial risk factors to major depression after childbirth. Soc. Psychiatry Epidimiol. 2005; 40(8): 605-612.

[29] Tychey C, Briancon S, Lighezzolo J, Spitz E, Kabuth B, De Luigi V et. al. Quality of life, postnatal depression and baby gender. J. clin. Nurs. 2007; 071012. 